Research Article

\title{
Study on the Strength Development of Cemented Backfill Body from Lead-Zinc Mine Tailings with Sulphide
}

\author{
Juanrong Zheng, ${ }^{1}$ Lijie Guo $\mathbb{D}^{2},{ }^{2}$ Xiaoxiao Sun, ${ }^{1}$ Wenchen Li, ${ }^{2}$ and Qi Jia ${ }^{3}$ \\ ${ }^{1}$ College of Civil Engineering, Zhengzhou University, Zhengzhou, Henan 450002, China \\ ${ }^{2}$ Beijing General Research Institute of Mining and Metallurgy, Beijing 100160, China \\ ${ }^{3}$ Department of Civil, Environmental and Natural Resources Engineering, Luleå University of Technology, 97187 Luleå, Sweden
}

Correspondence should be addressed to Lijie Guo; guolijie@bgrimm.com

Received 14 February 2018; Accepted 22 March 2018; Published 16 April 2018

Academic Editor: Giorgio Pia

Copyright (c) 2018 Juanrong Zheng et al. This is an open access article distributed under the Creative Commons Attribution License, which permits unrestricted use, distribution, and reproduction in any medium, provided the original work is properly cited.

\begin{abstract}
The unconfined compressive strength (UCS) development of cemented backfill materials for lead-zinc mine tailings with sulphide was studied. The results showed that the UCS of the cemented backfill body with ordinary Portland cement (OPC) as binder decreased in the later curing days, regardless of particle size. Under the same conditions, the higher the OPC content, the higher the UCS of the cemented backfill body, and the UCS of the cemented backfill body began to decrease at the longer curing days. Under the same conditions, the finer the tailings, the lower the UCS of the cemented backfill body at each age, and the UCS of the cemented backfill body began to decrease at the earlier curing age. X-ray diffraction analysis (XRD) showed that the reduction of the UCS of the cemented backfill body was related to the formation of an expansive substance (expansive gypsum) in the cemented backfill body, which led to the cracking of the test sample. In the cemented backfill materials of coarse tailings of lead-zinc mine, the composite binder formed by OPC and calcined kaolin (CK) containing metakaolin was used; the amount of calcium hydroxide, the hydration product of cement, was reduced or eliminated due to the pozzolanic reaction of metakaolin; and the amount of expansive gypsum was reduced or eliminated, so the UCS of the cemented backfill body increased within 360 days of curing.
\end{abstract}

\section{Introduction}

With the sustained and rapid growth of China's national economy, the mining industry has developed rapidly [1-3]. While the mining industry provides raw materials for the national economic construction, it also causes a series of problems that have a negative impact on the natural ecology and social economic life; for example, a large area of land is damaged, a large amount of solid waste is stacked on the earth's surface, and there are many underground goafs, which have become a major problem to be solved at present [4-7]. According to the modern mining concept, the solid waste filling technology is the most effective way to solve the series of problems caused by mining activities. The mining technique with filling has the function of eliminating ground depression caused by mining and improving the mining stress environment; the function of low dilution and loss exploit, improving efficiency of integration of resource; the function of hypothetical resources protection by "exploiting the abundant, preserving the poor"; the function of reducing solid waste discharge of waste rock and tailings and others, or even fundamentally eliminating mining end handling to achieve no-waste mining; and the function of adapting to the exploitation of various complicated and hard-to-mine deposits [8-11].

For nonferrous metal ore tailings, especially the tailings of lead-zinc mine, the sulphide (mainly pyrite, $\mathrm{FeS}_{2}$ ) is usually contained. The sulfur compound tailings have been used in the preparation of cemented backfill materials, and the longterm UCS of the cemented backfill body maintenance begins to decrease [12-16]. Benzaazoua et al. [11] produced various paste backfill mixtures by three tailings, that is, sulfur rich (32\% wt. and $24 \%$ wt. sulfur, resp.), medium grade for sulfur (16\% wt.) and low grade for sulfur (5\% wt.), six binder types, 
and six mixing-water types. It is found that the chemical properties of tailings, binders, and mixing water all affect the strength of solidified bodies; for low and medium sulfur tailings, the slag-based binder has stronger cementing ability than Portland cement and fly ash cement. Fall et al. [15] studied experimental characterization of the influence of tailings fineness and density on the quality of the cemented paste backfill. The sampled tailings were reprocessed to create several grain size classes corresponding to fine $(20 \mu \mathrm{m}$ particles $>60 \mathrm{wt} . \%$ ), medium (35-60 wt.\% of $20 \mu \mathrm{m}$ particles), and coarse (15-35 wt. $\%$ of $20 \mu \mathrm{m}$ particles) tailings. The finer the tailings material used, the greater the overall porosity of the $\mathrm{CPB}$ becomes.

In China, generally, the tailings coming out of the ore treatment plant (with solid content of about $20 \%-30 \%$ ) is transported to the tailings stock bin of the filling plant [17]. Coarse tailings (i.e., classified tailings) is released from the bottom of the stock bin (with the solid concentration of about $75 \%$ ) and mixed with the binder or piled up in open spaces (with the solid content up to 90\%) and then mixed with the binder and right amount of water, used for mining filling. The overflow tailings produced at the top of the stock bin (generally fine particles of less than $38 \mu \mathrm{m}$ ) are discharged into the tailings ponds [18]. With the construction of the green mines, the tailings ponds cannot be built any more, and the low-concentration overflow tailings must be subjected to the dense technology so that the solid content reaches about $60 \%-65 \%$ of paste, and then the binder is added to fill. In this paper, aiming at the features of coarse tailings and fine tailings in the sulfur compound lead-zinc ores that are unique to our country, by mixing the binder to form the cemented backfill material, the author makes a test research of the development rules of the long-term UCS of the cemented backfill body (i.e., the long-term stability of the cemented backfill body).

\section{Test Raw Materials and Test Methods}

\subsection{Test Raw Materials}

2.1.1. Tailings. The tailings selected in this paper are divided into coarse tailings (also known as classified tailings) and fine tailings (also known as overflow tailings), which are taken from a lead-zinc ore in South China. The essential minerals of coarse tailings and fine tailings are quartz, pyrite, limestone, dolomite, and white mica (Figure 1(a)). The particle size distribution of tailings was obtained by adopting the laser image analysis method; its physical and chemical properties are shown in Tables 1 and 2, in which the SSA is the specific surface area and $G_{s}$ is the specific gravity. Big differences are there for both the particle size distribution and chemical content of coarse tailings and fine tailings. The sulfur content of coarse and fine tailings are, respectively, $12.95 \%$ and $19.07 \%$, which belongs to middle content tailing [19]; the specific surface area of fine tailings is the largest in raw materials. The water contents of coarse and fine tailings transported from the mine to the laboratory are also different: the solid content of coarse tailings is $88.5 \%$ and that of fine tailings is $63 \%$.

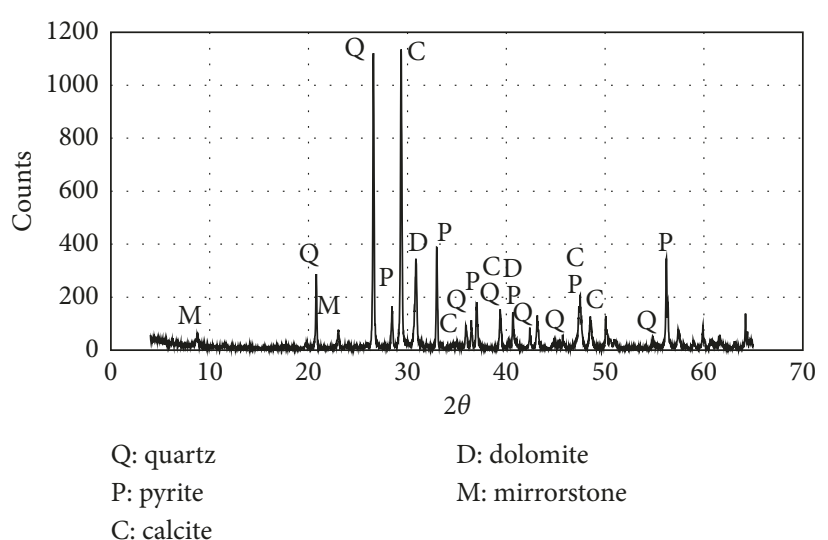

(a)

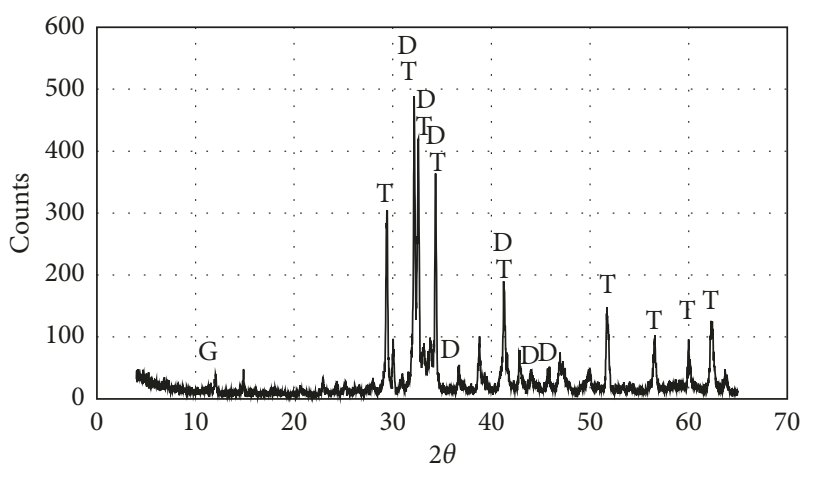

T: tricalcium silicate

D: dicalcium silicate

G: gypsum

(b)

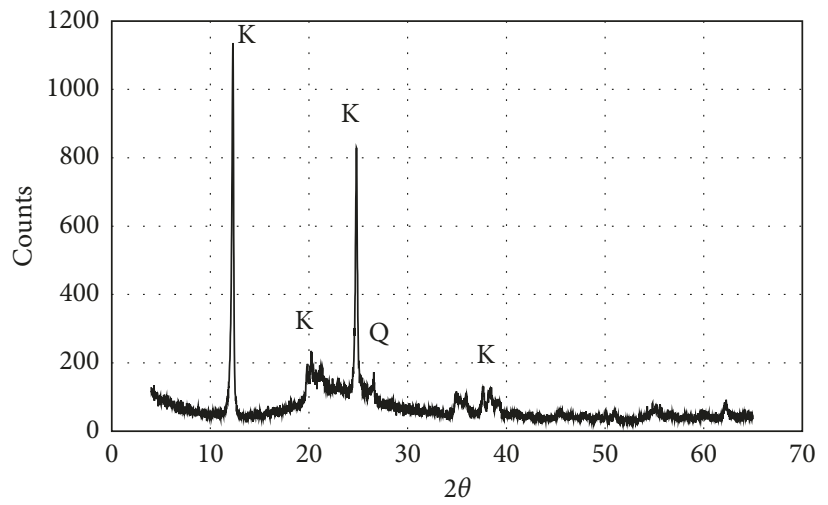

K: kaolin

Q: quartz

(c)

FIGURE 1: XRD profiles of tailings (a), OPC (b), and CK (c).

2.1.2. Binder. Cement is chosen as the binder in this paper. The physical and chemical properties of ordinary Portland cement (OPC) of 42.5 are shown in Tables 1 and 2. Other physical and mechanical properties of cement conform to national standards.

2.1.3. Supplementary Cementitious Material. The calcined kaolin is chosen as the supplementary cementitious material 
TABLe 1: Chemical properties of the binder and tailings used.

\begin{tabular}{|c|c|c|c|c|c|c|c|c|c|c|}
\hline Chemical composition & $\mathrm{SiO}_{2}$ & $\mathrm{Al}_{2} \mathrm{O}_{3}$ & $\mathrm{FeO}$ & $\mathrm{CaO}$ & $\mathrm{MgO}$ & $\mathrm{Pb}$ & $\mathrm{Zn}$ & $\mathrm{Cu}$ & $S$ & Loss \\
\hline Coarse tailings & 32.07 & 3.59 & 12.28 & 18.14 & 1.58 & 0.50 & 0.65 & 0.07 & 12.95 & 11.38 \\
\hline Fine tailings & 25.37 & 5.88 & 14.28 & 12.47 & 0.15 & 0.84 & 0.54 & 0.28 & 19.07 & 19.97 \\
\hline OPC & 25.26 & 6.38 & 4.05 & 54.67 & 2.68 & - & - & - & 0.06 & - \\
\hline $\mathrm{CK}$ & 43.13 & 45.17 & 1.25 & 1.75 & 0.10 & - & - & - & - & 7.70 \\
\hline
\end{tabular}

TABle 2: Physical properties of the binder and tailings used.

\begin{tabular}{lccccccccc}
\hline Physical properties & $\mathrm{SSA}\left(\mathrm{m}^{2} / \mathrm{kg}\right)$ & $\mathrm{G}_{\mathrm{s}}(-)$ & $>90 \mu \mathrm{m}(\%)$ & $>45 \mu \mathrm{m}(\%)$ & $\mathrm{D} 10(\mu \mathrm{m})$ & $\mathrm{D} 60(\mu \mathrm{m})$ & $\mathrm{Cu}(-)$ & $\mathrm{Cc}(-)$ & $<20 \mu \mathrm{m}(\%)$ \\
\hline Coarse tailings & 98 & 3.00 & 30.67 & 60.64 & 12.67 & 74.25 & 5.86 & 1.31 & 12.86 \\
Fine tailings & 633.8 & 3.00 & 1.07 & 7.28 & 1.50 & 14.68 & 9.8 & 0.94 & 73.67 \\
OPC & 461.9 & 3.08 & - & 5.67 & 5.12 & 18.28 & 3.6 & 0.90 & 65.65 \\
CK & 588.1 & 2.62 & 1.44 & 13.11 & 1.31 & 17.97 & 13.72 & 0.98 & 68.69 \\
\hline
\end{tabular}

in this paper. Calcined kaolin (CK) is a commercially available product which is produced by roasting coal property kaolin. The pozzolanic activity of this product is demarcated $1050 \mathrm{mg} \mathrm{Ca}(\mathrm{OH})_{2} / \mathrm{g} \mathrm{CK}$ by the factory. Other physical and chemical properties are shown in Tables 1 and 2. $\mathrm{X}$-ray diffraction (XRD) diagram of $\mathrm{CK}$ is as shown in Figure 1(c), in which a lot of not fully calcined original kaolin and small amounts of quartz crystal are in CK; amorphous material metakaolin (MK) is also obvious (the baseline of XRD figure rises).

2.1.4. Mixing Water. The mixing material reaches the designed slump and needs to be replenished. The supplementary mixture water in this paper is the urban tap water.

\subsection{Test Method}

2.2.1. Mixture Proportion and Test Sample Preparation. The mix proportion and partial performance of the mixture are shown in Table 3. A total of $132 \mathrm{CPB}$ samples were subjected to UCS tests after $3,7,14,28,56,90,120,150,180,270$, and 360 days of curing periods.

(1) Test Sample Preparation. Put the wet tailings, cement, supplementary cementitious materials, and water into the agitating pan in accordance with the specified requirements and proportion and use the mortar agitator for self-motion stirring (at low speed for $60 \mathrm{~s}$, high speed for $30 \mathrm{~s}$, stop for $90 \mathrm{~s}$, and again high speed for $60 \mathrm{~s} ; 240 \mathrm{~s}$ in total) for the preparation of the sample. And then pour it into a $70.7 \mathrm{~mm} \times 70.7 \mathrm{~mm} \times 70.7 \mathrm{~mm}$ test die, the surface being covered with fresh-keeping membrane (extra water can come off between the side face and bottom of the test die), let it stand at $20^{\circ} \mathrm{C} \pm 5^{\circ} \mathrm{C}$ indoor for three days before taking apart the die, and place the naked test sample into the standard curing box $\left(20^{\circ} \mathrm{C} \pm 1^{\circ} \mathrm{C}\right.$, humidity is greater than $90 \%$ ) for maintenance until the stipulated curing age for the performance test.

(2) Unconfined Compressive Strength (UCS). Proceed according to the method stipulated in cement mortar strength test methods (ISO) (GB17671-1999), but the actual compression area of the test sample should be measured.

C20CK0 in Table 3 is set according to the requirements (i.e., fresh filling body is transported mine goaf by self-flow and UCS of 3.0 MPa at curing 3 days) of filling body adopted in a mine in China, so the slump of slurry is set $260 \mathrm{~mm}$. The goal is to observe the long-term UCS of C20CK0 in the lab.

2.2.2. XRD and MIP Analysis. When the test sample comes to the specified curing age, after the UCS is tested, select a representative sample (from both the surface and the center of the test samples), soak with acetone for 24 hours to end the hydration reaction of the binder, and then put it into a drying oven of $60^{\circ} \mathrm{C}$ to go on with drying for XRD analysis and mercury intrusion porosimeter (MIP) studies.

The XRD analysis conditions adopted in this paper is as follows: the instrument is an XRD analysis meter of D/Max2500 PC with a copper target on that is made in Japan, scanning angle $2 \theta$ ranging from $4^{\circ}$ to $60^{\circ}$, and the scanning speed is $2^{\circ} / \mathrm{min}$.

The MIP used in this study is AutoPore IV 9500 V1.05. Applying pressures ranged from 0 to $414 \mathrm{MPa}(60,000 \mathrm{psi})$, allowing throat pore diameter measurements down to $0.003 \mu \mathrm{m}$. MIP is analyzed according to the ISO 15901-1: 2005 standard. In this study, mercury surface tension $\sigma$ and mercury contact angle $\theta$ are taken as $485 \mathrm{dynes} / \mathrm{cm}$ and $130^{\circ} \mathrm{C}$, respectively.

\section{Results and Discussion}

3.1. Property of Mixture. It can be seen from Table 3 that only $7 \%$ OPC (counted by total solid mass) is added in the coarse tailings, and the bleeding rate of the mixture reaches $20.2 \%$ when the slumps are controlled at pumpable $180 \mathrm{~mm}$. Continue to increase OPC to $20 \%$ (counted by total solid mass), and the bleeding rate of the mixture reaches $26.3 \%$ when the slumps are controlled at a gravity transportation of $260 \mathrm{~mm}$. The result shows that only OPC is mixed in the coarse tailings; both pumping transportation and gravity transportation can be used, but the bleeding rate is too large, and the mixture is not cement paste filling material. When 7\% OPC and 10\% (counted by total solid mass) supplementary cementitious 
TABLE 3: Mix proportions and partial properties of the mixtures.

\begin{tabular}{|c|c|c|c|c|c|c|c|c|c|}
\hline \multirow[b]{2}{*}{ Number } & \multicolumn{5}{|c|}{ Proportion of mixture } & \multicolumn{4}{|c|}{ Partial properties of mixture } \\
\hline & $\begin{array}{l}\text { Wet coarse } \\
\text { sailings (g) }\end{array}$ & $\begin{array}{l}\text { Wet fine } \\
\text { sailings (g) }\end{array}$ & $\begin{array}{c}\text { OPC } \\
(\mathrm{g})\end{array}$ & $\begin{array}{l}\text { CK } \\
(g)\end{array}$ & $\begin{array}{l}\text { Water } \\
(\mathrm{g})\end{array}$ & $\begin{array}{c}\text { Solid } \\
\text { concentration (\%) }\end{array}$ & $\begin{array}{l}\text { Wet density } \\
\left(\mathrm{kg} / \mathrm{m}^{3}\right)\end{array}$ & $\begin{array}{c}\text { Slumps } \\
(\mathrm{mm})\end{array}$ & $\begin{array}{c}\text { Bleeding rate } \\
(\%)\end{array}$ \\
\hline C20CK0 & 904 & - & 200 & - & 211 & 76.0 & 2073 & 260 & 26.3 \\
\hline C7CK0 & 1051 & - & 70 & - & 166 & 77.7 & 2210 & 180 & 20.2 \\
\hline C7CK10 & 938 & - & 70 & 100 & 142 & 80.0 & 2235 & 180 & 0.5 \\
\hline XC20CK0 & - & 1111 & 200 & 100 & 176 & 63.0 & 1785 & 180 & 0.8 \\
\hline
\end{tabular}

materials (calcined kaolin) are mixed in the coarse tailings and when the slumps are controlled at $180 \mathrm{~mm}$, the bleeding rate of the mixture is only $0.5 \%$. It is cement paste filling the material; the wet density increases significantly; the result is relevant to that the particle fineness of calcined kaolin $(\mathrm{CK})$ is approximately lower than that of the cement particle; the fine particles may fill the gap between the comparatively coarse particles, thus the particle composition is more reasonable, and wet compactness increases. The solid concentration of the fine tailings used in this paper is $63 \%$, which appears to be pasty fluid, and when $20 \%$ OPC is mixed, the slumps of the mixture are $180 \mathrm{~mm}$ and the bleeding rate is only $0.8 \%$, which is a kind of cementing paste filling the material.

\subsection{Law of Development of the UCS of the Cemented Backfill} Body. The relationship between the UCS and curing age of the cemented backfill body is shown in Figure 2.

It can be seen from Figure 2 that when only 7\% OPC is added into the coarse tailings and the slumps are controlled at pumpable $180 \mathrm{~mm}$ at $28 \mathrm{~d}$, the UCS of the cemented backfill body improves with extension of the curing age, but then the UCS decreases till $360 \mathrm{~d}$; the UCS of the cemented backfill body drops from $1.733 \mathrm{MPa}$ (at $28 \mathrm{~d}$ ) to $1.026 \mathrm{MPa}$ (at $360 \mathrm{~d}$ ), falling at a rate of $40.8 \%$. When only $20 \%$ OPC is added into the coarse tailings and the slumps are controlled at the gravity transportation of $180 \mathrm{~mm}$ at $120 \mathrm{~d}$, the UCS of the cemented backfill body improves with extension of the curing age, but then the UCS decreases till $360 \mathrm{~d}$; the UCS of the cemented backfill body drops from $13.880 \mathrm{MPa}$ (at $120 \mathrm{~d}$ ) to $9.30 \mathrm{MPa}$ (at $360 \mathrm{~d}$ ), falling at a rate of $33.0 \%$. When only $20 \%$ OPC is added into the fine tailings and the slumps are controlled at pumpable $180 \mathrm{~mm}$ at $90 \mathrm{~d}$, the UCS of the cemented backfill body improves with extension of the curing age, but then the UCS decreases till $360 \mathrm{~d}$; the UCS of the cemented backfill body drops from $2.755 \mathrm{MPa}$ (at $90 \mathrm{~d}$ ) to $0.321 \mathrm{MPa}$ (at $360 \mathrm{~d}$ ), falling at a rate of $88.3 \%$. However, when only $7 \%$ OPC and $10 \%$ supplementary cementitious material (calcined kaolin) are mixed into the coarse tailings and the slumps are controlled at $180 \mathrm{~mm}$, curing the cemented backfill body for $360 \mathrm{~d}$, the UCS does not decrease; the UCS increases quickly in the curing age of $28 \mathrm{~d}$; during the curing age from $28 \mathrm{~d}$ to $360 \mathrm{~d}$, the UCS slightly grows; the UCS of the cemented backfill body increases from $3.336 \mathrm{MPa}$ (at $28 \mathrm{~d}$ ) to $4.067 \mathrm{MPa}$ (at $360 \mathrm{~d}$ ), increasing at a rate of $21.9 \%$.

The above results show that for the tailings of the sulfur compound lead-zinc ore, no matter it is coarse fillings or fine fillings, only mixed with OPC as the binder, the UCS of the cemented backfill body decreases in the later period.

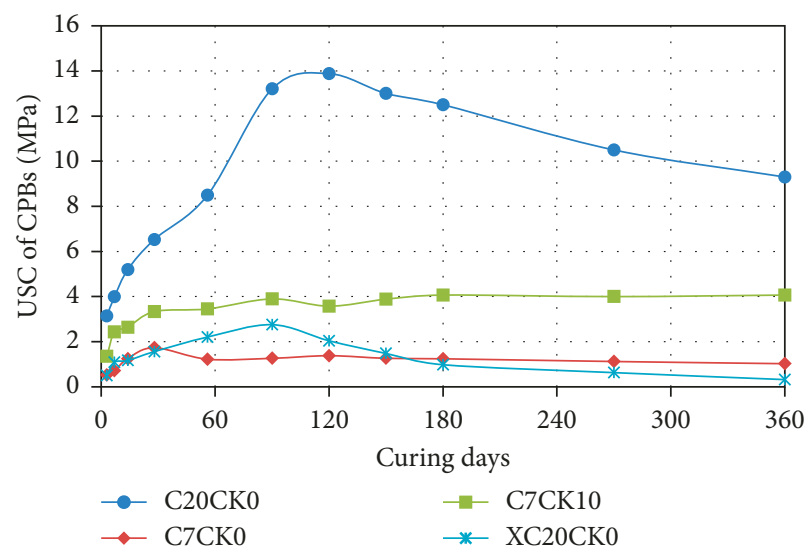

FIgURE 2: Relationship between UCS and curing days of the cemented backfill bodies.

Compared with the cemented backfill bodies with the low cement content, for those with the high cement content, the UCS of each curing age is higher and the UCS begins to decline with a longer curing age. When the cement content is the same, compared with the coarse tailings cemented backfill bodies, for the fine tailings cemented backfill bodies, the UCS of each curing age is lower and the UCS begins to decline at an earlier curing age, and the decrease rate of UCS is even greater. In the coarse tailings, in addition to the cement binder, adding calcined kaolin which contains metakaolin is beneficial to the long-term stability of the tailings cemented backfill body in sulfur compound lead-zinc ore.

\subsection{Theoretical Analysis}

3.3.1. Cracking of Cemented Backfill Body. The cracking of the cemented backfill body is shown in Figure 3.

As can be seen from Figure 3, for the tailings in sulfur compound lead-zinc ore, no matter it is coarse fillings or fine fillings, only by being mixed with OPC as the binder and curing the cemented backfill body for $360 \mathrm{~d}$, there will be visible cracks on all cemented backfill bodies, and the cracking of the fine tailings test samples is the most serious; in the coarse tailings, in addition to the cement-mixed binder, by again mixing in the cemented backfill body of calcined kaolin that contains metakaolin and having it cured for $360 \mathrm{~d}$, the cemented backfill body test sample will be intact, without visible cracks. The result has congruent relationship with the law of development of the UCS of the cemented backfill body. There is crack in the test sample whose UCS decreases in the later stage of the cemented 


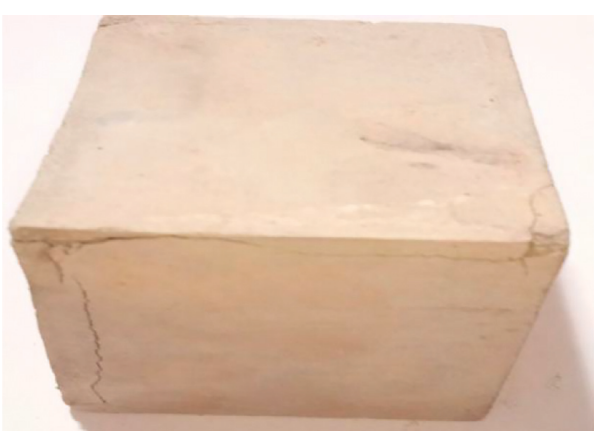

(a)

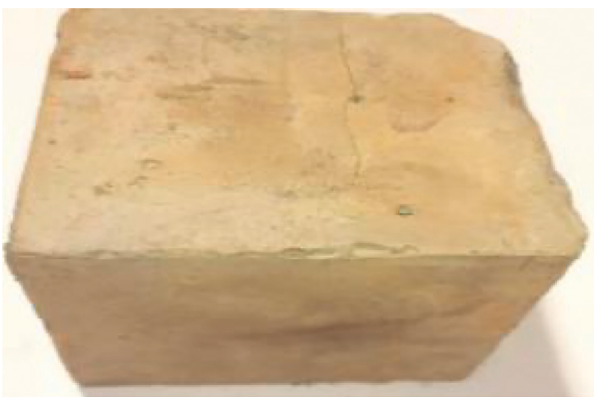

(b)

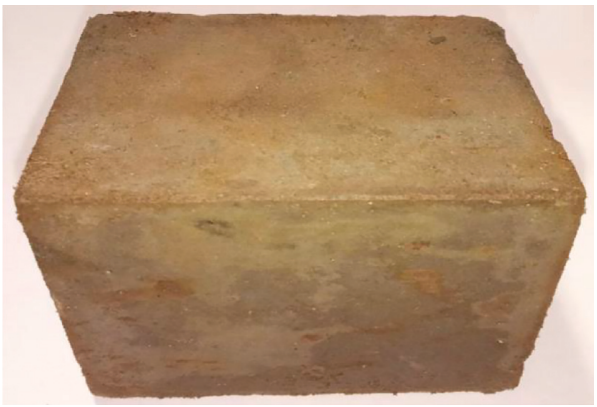

(c)

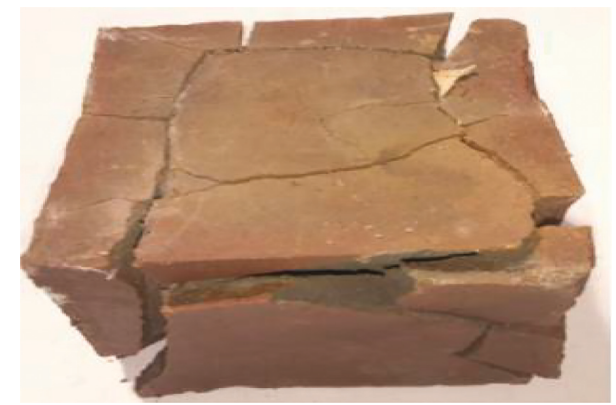

(d)

Figure 3: Visual appearance of cemented backfill bodies at $360 \mathrm{~d}$.

backfill body; for the noncrack test sample, the UCS in the later stage is of stable development, which indicates that the decrease of the UCS of the test sample is caused by the crack of the test sample.

3.3.2. XRD Analysis. XRD figure $(360 \mathrm{~d})$ of cemented backfill bodies C20K0 (a), C7K0 (b), C7K10 (c) and XC20K0 (d) are shown in Figure 4.
As can be seen from Figure 4, for the tailings in sulfur compound lead-zinc ore, no matter it is coarse filling or fine filling, only by being mixed with OPC as the binder and curing the cemented backfill body for $360 \mathrm{~d}$, there will be XRD diffraction peak of dihydrate gypsum for all cemented backfill bodies, and the XRD diffraction peak of dihydrate gypsum of the fine tailings test sample is the highest; in the coarse tailings, in addition to the cement-mixed binder, by mixing in the cemented backfill body of calcined kaolin that contains metakaolin and having it cured for $360 \mathrm{~d}$, there will be no XRD diffraction peak of dihydrate gypsum in the cemented backfill body test sample. This result is consistent with the cracking pattern of cemented backfill bodies, which indicates that the crack of the test sample is caused by the production of dihydrate gypsum in the test sample.

In order to find out how the dihydrate gypsum in the test sample is produced, in this paper, the product of the hydration within $3 \mathrm{~d}$ of OPC paste (water cement ratio of 0.35 ) is analyzed first, and the results are shown in Figure 5.

It can be seen from Figure 5 that the characteristic peak of the XRD figure of the OPC paste sample hydrated for $1 \mathrm{~h}$ is mainly gypsum and mineral clinker in cement, but no hydration products such as calcium hydroxide and ettringite and others are present. In the XRD figure for $6 \mathrm{~h}$ of hydration reaction, the characteristic peak of ettringite and calcium hydroxide crystals begins to appear, which indicates that the hydration reaction of the cement gets under way after $6 \mathrm{~h}$. After $1 \mathrm{~d}$ of hydration, the characteristic peak of calcium alum and calcium hydroxide crystals has obviously appeared, and the characteristic peak intensity of $\mathrm{Ca}(\mathrm{OH})_{2}$ is significantly enhanced compared with that of $6 \mathrm{~h}$, while the peak strength of original mineral clinker and gypsum decreases significantly. Therefore, by comparing the $\mathrm{X}$-ray diffraction diagrams at four time points of OPC, it can be seen that as the processing of hydration reaction $(6 \mathrm{~h}-7 \mathrm{~d})$, the mineral clinker and gypsum in cement reduces gradually, and the amount of hydration products of ettringite and calcium hydroxide crystal is on the rise. According to the transformation law of hydration products of OPC hydration alone, it can be concluded that by mixing OPC in the sulfur compound coarse and fine tailings, curing for $360 \mathrm{~d}$, a large number of dihydrate gypsum (i.e., secondary gypsum) is formed in the curing process of the cemented backfill body.

A series of complex chemical reactions occur after the tailings containing pyrite $\left(\mathrm{FeS}_{2}\right)$ are mixed with $\mathrm{OPC}$ and water. First, cement and water react to produce the main hydration products like hydrated calcium silicate gel and calcium hydroxide crystals, a small amount of gypsum and ettringite, and others. Figure 4 shows that no matter coarse tailing or fine tailing, ettringite is not checked out in the cemented backfill bodies that mixed in with OPC, and the peak value of a small amount of hydrated gypsum and ettringite of OPC cannot be checked out, which probably because it is too small. Second, the pyrite in the tailings is decomposed, and $\mathrm{Fe}_{2} \mathrm{O}_{3}$ and sulphuric acid are generated under the joint action of water and oxygen, in which the sulfate radical reacts with the hydration products of cement calcium hydroxide of cement and produce calcium sulfate dihydrate [20]. The reaction equations are as follows: 


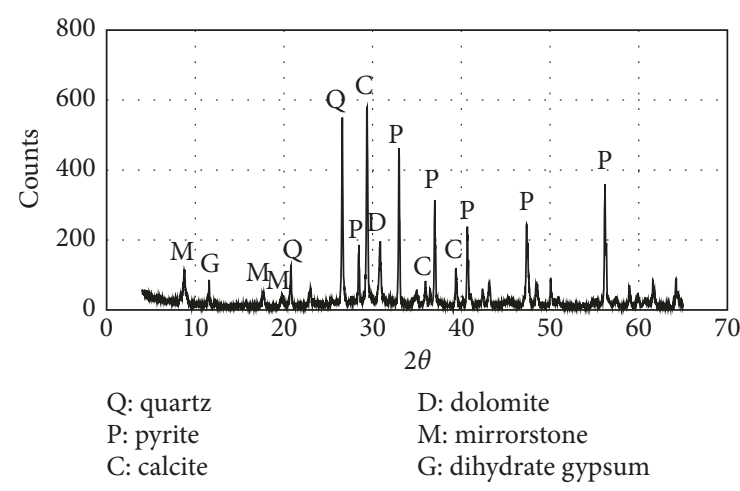

(a)

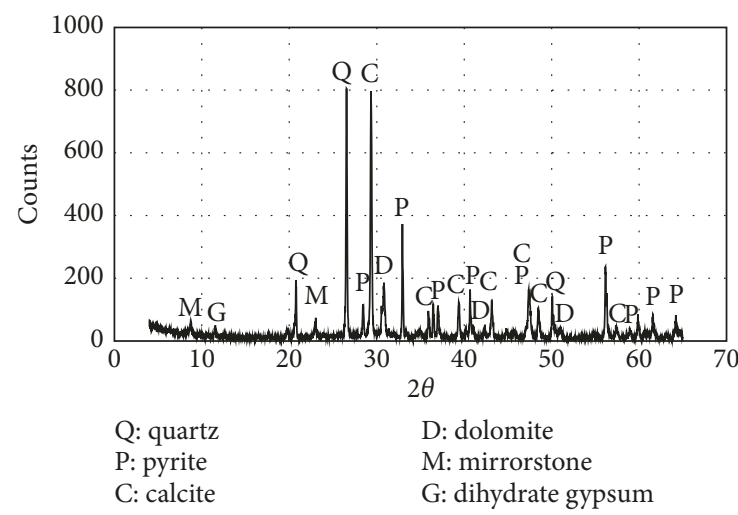

(b)

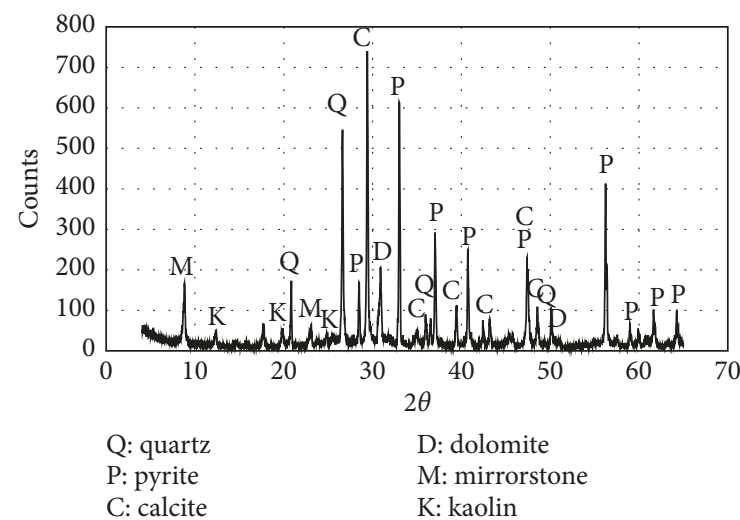

(c)

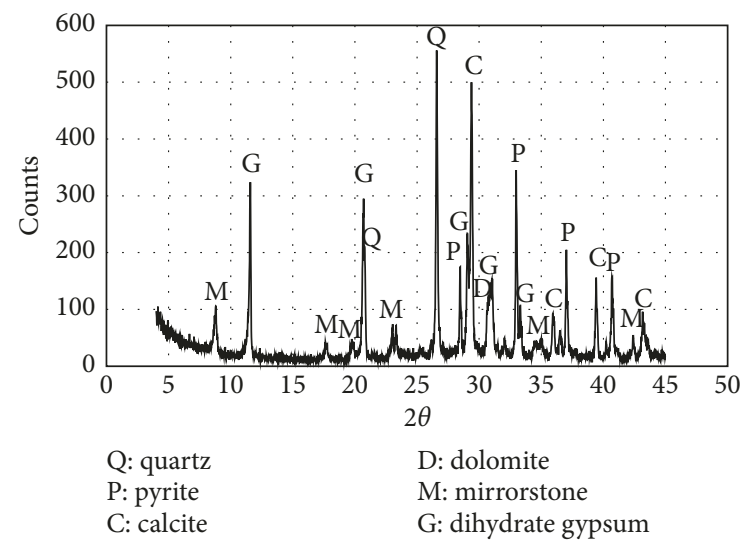

(d)

FIGURE 4: X-ray diffraction of the cemented backfill bodies at $360 \mathrm{~d}$.

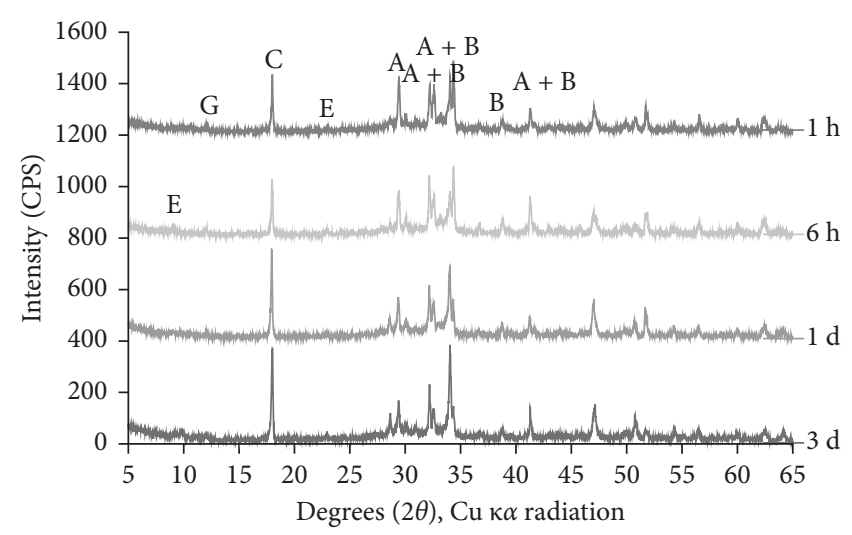

Figure 5: X-ray diffraction of OPC paste with different curing days. A: tricalcium silicate; B: dicalcium silicate; C: calcium hydroxide; Q: quartz; G: dihydrate gypsum; E: ettringite.

$$
\begin{array}{r}
4 \mathrm{FeS}_{2}+15 \mathrm{O}_{2}+8 \mathrm{H}_{2} \mathrm{O} \rightarrow 2 \mathrm{Fe}_{2} \mathrm{O}_{3}+8 \mathrm{SO}_{4}{ }^{2-}+16 \mathrm{H}^{+} \\
\mathrm{Ca}(\mathrm{OH})_{2}+\mathrm{SO}_{4}^{2-}+2 \mathrm{H}_{2} \mathrm{O} \rightarrow \mathrm{CaSO}_{4} \cdot 2 \mathrm{H}_{2} \mathrm{O}+2 \mathrm{OH}^{-}
\end{array}
$$

According to the above reaction, for the dihydrate gypsum formed by the sulfate radical from the tailings and the cement hydration product calcium hydroxide, after the solidification of the slurry, dihydrate gypsum is formed (called as the secondary gypsum). The formation of secondary gypsum is a volume expansion process; at the beginning stage of the cemented backfill body, the secondary gypsum fills the small openings of the cemented backfill body, which is good for strength. When the amount of gypsum formed is overmuch, the expansive force generated overpasses the extension strength of the cemented backfill body, then the test sample cracks, and the UCS reduces. In the tailings, if the amount of ordinary cement is increased, the UCS and extension strength of the cemented backfill body are both increased, so the curing age for the reduction of the UCS of the cemented backfill body is prolonged. The finer the tailings particles are, the easier they are to oxidize; the higher the sulfate radical concentration is, the higher the amount of secondary gypsum produced is; the larger the swelling force is, the more severe the cracking is and the greater the reduction of the UCS of the test sample is.

When a certain amount of calcined kaolin that contains metakaolin (CK) is mixed in the slurry of coarse tailings, cement and water, the metakaolin has a strong adsorption and reaction (pozzolanic reaction) ability with calcium hydroxide, thereby reducing or eliminating the amount of cement hydration products of calcium hydroxide; as a result, the amount of dihydrate gypsum formed is reduced or eliminated. The conclusion is that in the cemented backfill material, the composite binder that is formed by being mixed with OPC and calcined kaolin that contains metakaolin is beneficial for the long-term stability of the cemented backfill body of the sulfur compound tailings.

3.3.3. MIP Analysis. The changes in cumulative $\mathrm{Hg}$ intrusion porosity and incremental pore size distribution (PSD) curves for 28-day cured CPB samples are plotted as shown in Figure 6. 


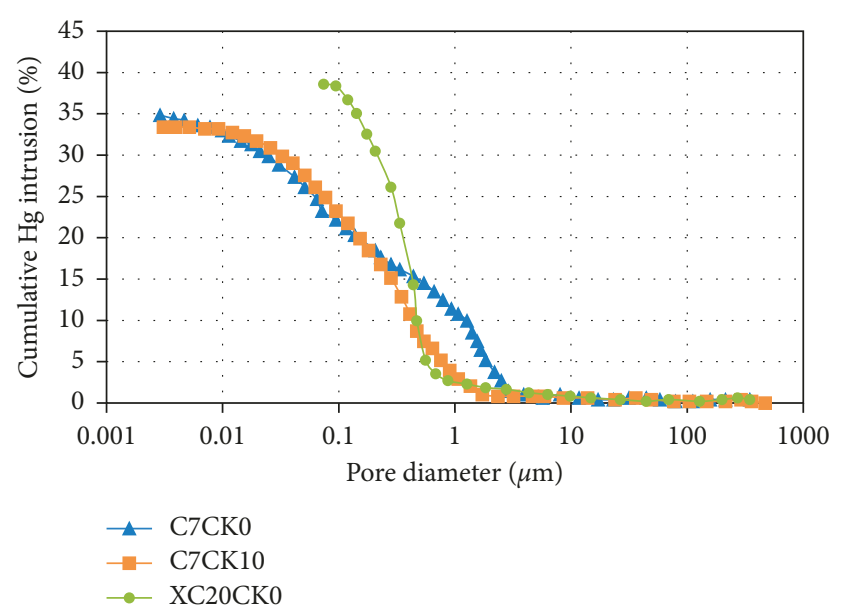

(a)

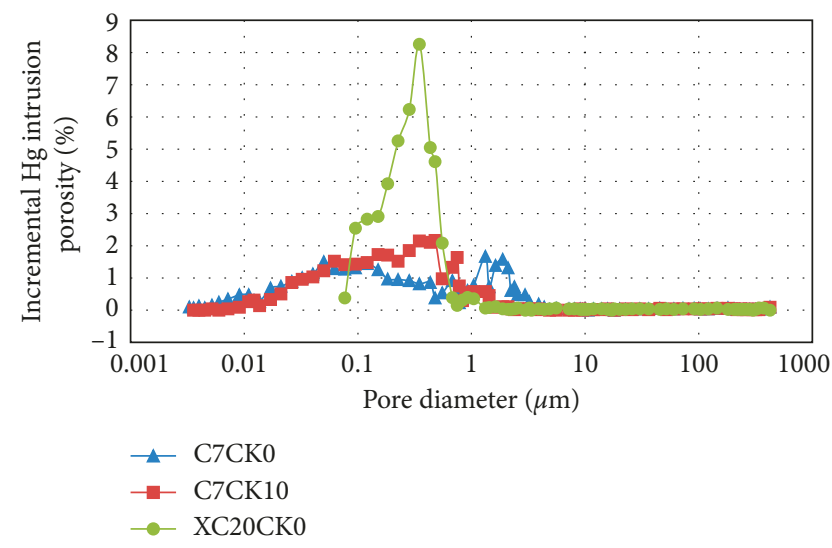

(b)

Figure 6: The relationships between $\mathrm{Hg}$ intrusion porosity and pore diameter.

Figure 6 shows that an increase in the amount of fine tailings in $\mathrm{CPB}$ mixture (C7CK0 and XC20CK0 comparison) increases the total porosity and the incremental PSD curves shift toward smaller diameters with adding fine tailings. These results are consistent with previous research findings [15]. Combined with the results of XRD analysis (Figures 4(b) and 4(d)), there is a conclusion that an increase in the amount of fine tailings in $\mathrm{CPB}$ mixture increases the total porosity, which aggravates the oxidation of sulphide tailings with a consequent increase in strength loss. However, Figure 6 also shows that adding 10\% $\mathrm{CK}$ in $\mathrm{CPB}$ mixture (C7CK0 and C7CK10 comparison) decreases the total porosity and the incremental PSD curves shift toward smaller diameters with adding $\mathrm{CK}$, which prevents the oxidation of sulphide tailings with a consequent decrease in strength loss. These findings suggest the pore-filling and pozzolanic effect of the ground CK.

\section{Conclusion}

(1) For the tailings of the sulfur compound lead-zinc ore, no matter it is coarse fillings or fine fillings, only when mixed with OPC as the binder, the UCS of the cemented backfill body decreases in the later period.
(2) Under the same conditions, the higher the OPC content, the higher the UCS of the cemented backfill body, and the UCS of the cemented backfill body began to decrease at the longer curing days. Under the same conditions, the finer the tailings, the lower the UCS of the cemented backfill body at each age, and the UCS of the cemented backfill body began to decrease at the earlier curing age.

(3) The reduction of the UCS of the cemented backfill body was related to the formation of an expansive substance (expansive gypsum) in the cemented backfill body, which caused the cracking of the test sample. In the cemented backfill material, the composite binder that is formed by being mixed with OPC and calcined kaolin that contains metakaolin is beneficial for the long-term stability of the cemented backfill body of the sulfur compound tailings.

\section{Conflicts of Interest}

The authors declare that they have no conflicts of interest.

\section{Acknowledgments}

This research is supported by the International Science and Technology Cooperation Program of China (no. 2017YFE0107000), the National Key Research and Development Program of China (2016YFC0600709), the Youth Science and Technology Innovation Fund Project of BGRIMM (Q-28), and the National Key Research and Development Program of China (YS2017YFGH000511).

\section{References}

[1] Q. Dengpan, C. Weihua, Z. Lei et al., "Modern mining ideas and filling mining," Nonferrous Metals Science and Engineering, vol. 2, no. 2, pp. 7-14, 2011.

[2] Q. Jianping, J. Wenying, and N. Yunfei, "Geochemical study of heavy metal pollution in mine-river system," Mineral Rock Geochemical Bulletin, vol. 29, no. 1, pp. 74-82, 2010.

[3] Z. Aimin, Mine Waste Commented Filling, Metallurgical Industry Press, Beijing, China, 2007.

[4] A. Kesimal, E. Yilmaz, B. Ercikdi, I. Alp, and H. Deveci, "Effect of properties of tailings and binder on the short- and long-term strength and stability of cemented paste backfill," Materials Letters, vol. 59, no. 28, pp. 3703-3709, 2005.

[5] A. Tarig and M. Nehdi, "Developing durable paste backfill from sulphidic tailings," Waste and Resource Management, vol. 160, no. 4, pp. 155-166, 2007.

[6] M. Fall and M. Benzaazoua, "Modelling the effect of sulphate on strength development of paste backfill and binder mixture optimization," Cement and Concrete Research, vol. 35, no. 2, pp. 301-314, 2005.

[7] B. Ercikdi, A. Kesimal, F. Cihangir, H. Deveci, and I. Alp, "Cemented paste backfill of sulphate-rich tailings: importance of binder type and dosage," Cement and Concrete Composites, vol. 31, no. 4, pp. 268-274, 2009.

[8] B. Ercikdi, F. Clhangir, A. Kesimal, H. Deveci, and I. Alp, "Utilization of industrial waste products as pozzolanic material in cemented paste backfill of high sulphide tailings," Journal of Hazardous Materials, vol. 168, no. 2-3, pp. 848-856, 2009. 
[9] B. Ercikdi, G. Külekci, and T. Yilmaz, "Utilization of granulated marble and waste bricks as mineral admixture in cemented paste backfill of sulphide-rich tailings," Construction and Building Materials, vol. 93, pp. 573-583, 2015.

[10] B. Ercikdi, F. Clhangir, A. Kesimal, H. Deveci, and I. Alp, "Utilization of water-reducing admixtures in cemented paste backfill of sulphide-rich tailings," Journal of Hazardous Materials, vol. 179, no. 1-3, pp. 940-946, 2010.

[11] M. Benzaazoua, T. Belem, and B. Bussiere, "Chemical factors that influence the performance of mine sulphidic paste backfill," Cement and Concrete Research, vol. 32, no. 7, pp. 1133-1144, 2002.

[12] L. Guo, X. Peng, X. Yang et al., "Industrial practice on optimizing tailings composition combined with ore concentration processes," in Proceedings of the 12th International Conference on Mining with Backfill 2017; Society for Mining, Metallurgy and Exploration, pp. 69-79, Denver, CO, USA, February 2017.

[13] J. R. Barret and M. A. Coulthard, "Determination of fill stability, mining with backfill," in Proceedings of the 12th Canadian Rock Mechanics Symposium, Canadian Institute of Mining and Metallurgy, pp. 85-91, Montreal, QC, Canada, 1978.

[14] E. Yilmaz, T. Belem, and M. Benzaazoua, "Specimen size effect on strength behavior of cemented paste backfills subjected to different placement conditions," Engineering Geology, vol. 185, pp. 52-62, 2015.

[15] M. Fall, M. Benzaazoua, and S. Ouellet, "Experimental characterization of the influence of tailings fineness and density on the quality of cemented paste backfill," Minerals Engineering, vol. 18, no. 1, pp. 41-44, 2005.

[16] K. Klein and D. Simon, "Effect of specimen composition on the strength development in cemented paste backfill," $\mathrm{Ca}$ nadian Geotechnical Journal, vol. 43, no. 3, pp. 310-324, 2006.

[17] X. W. Yi, G. W. Ma, and A. Fourie, "Compressive behaviour of fibre-reinforced cemented paste backfill," Geotextiles and Geomembranes, vol. 43, no. 3, pp. 207-215, 2015.

[18] L. Li and M. Aubertin, "A modified solution to assess the required strength of exposed backfill in mine stopes," Canadian Geotechnical Journal, vol. 49, no. 8, pp. 994-1002, 2012.

[19] G. Liu, L. Li, X. Yang, and L. Guo, "Stability analyses of vertically exposed cemented backfill: a revisit to Mitchell's physical model tests," International Journal of Mining Science and Technology, vol. 26, no. 6, pp. 1135-1144, 2016.

[20] S. Ouellet, B. Bussiere, M. Mbonimpa, M. Benzaazoua, and M. Aubertin, "Reactivity and mineralogical evolution of an underground mine sulphidic cemented paste backfill," Minerals Engineering, vol. 19, no. 5, pp. 407-419, 2006. 


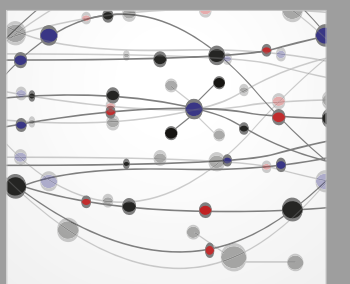

The Scientific World Journal
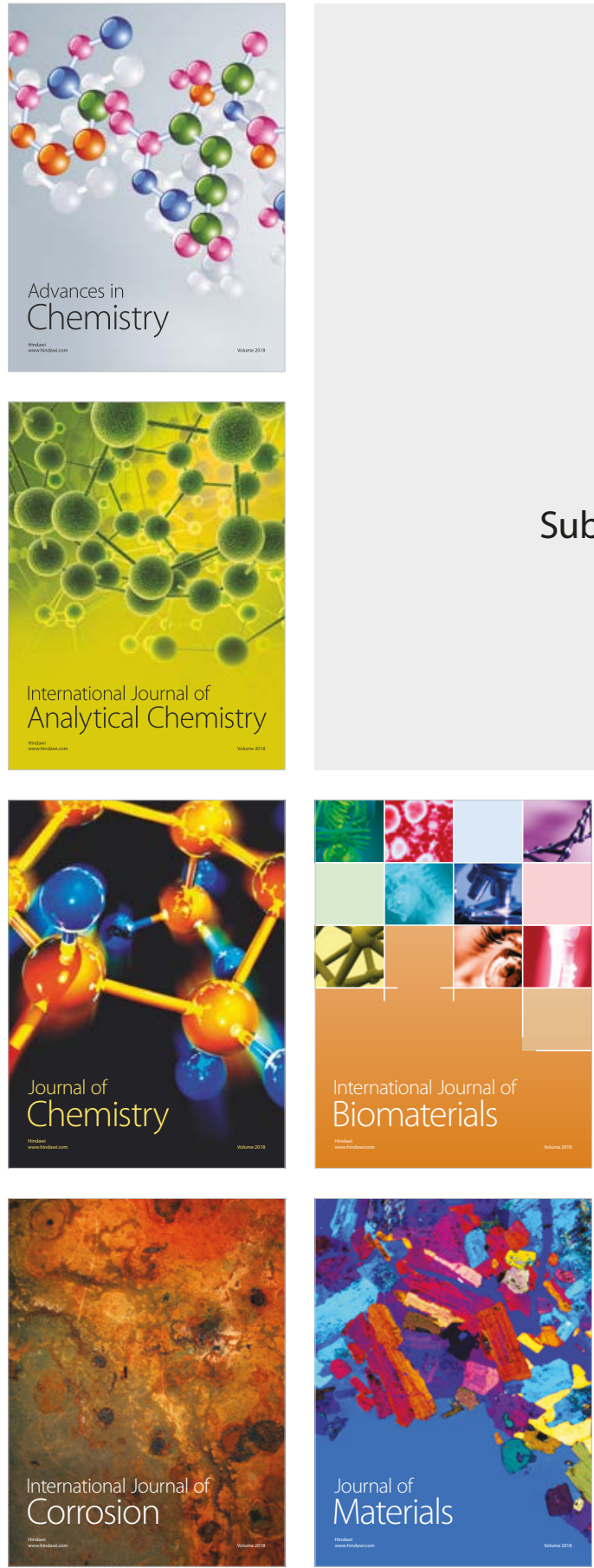

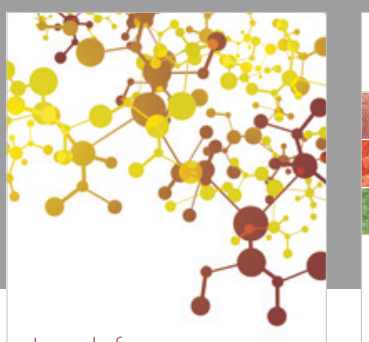

Journal of

Applied Chemistry
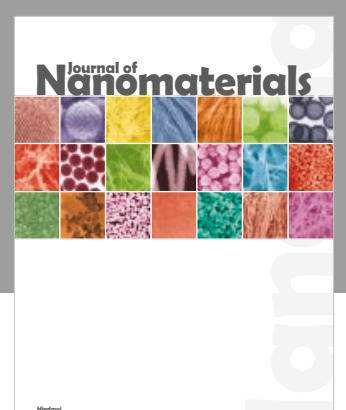

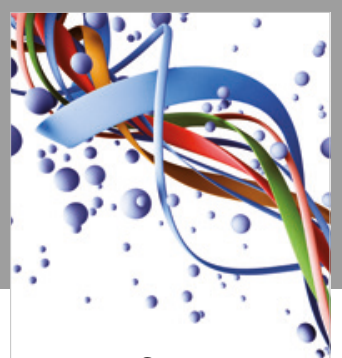

Scientifica

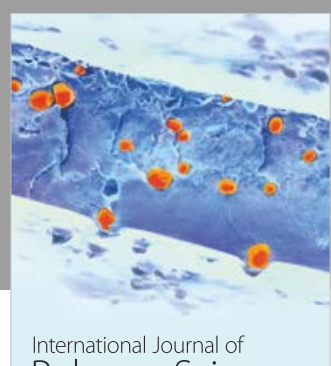

Polymer Science

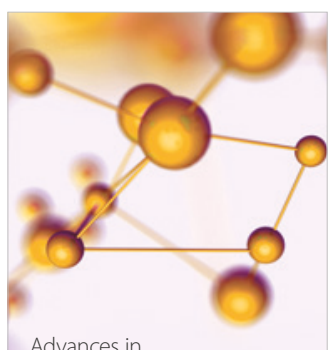

Physical Chemistry
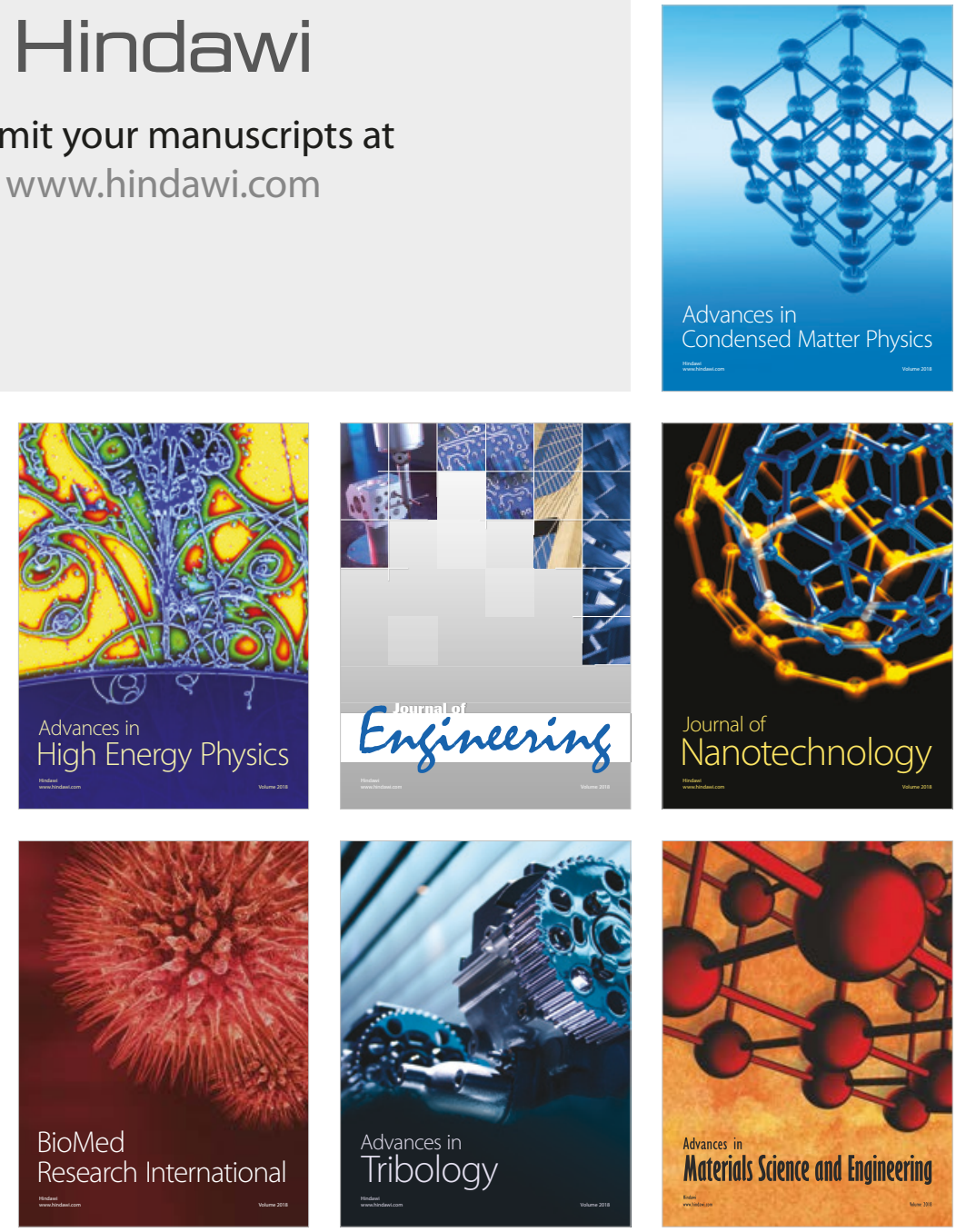